\title{
Targeted Therapies for Hepatocellular Carcinoma
}

\author{
Augusto Villanueva ${ }^{1,2}$ and Josep M. Llovet ${ }^{1,2,3,4}$ \\ ${ }^{1} \mathrm{HCC}$ Translational Research Laboratory, Barcelona-Clinic Liver Cancer Group, Institut \\ d'Investigacions Biomèdiques August Pi i Sunyer (IDIBAPS), Liver Unit, Hospital Clinic, \\ Barcelona, Catalonia, Spain. \\ ${ }^{2}$ Centro de Investigación Biomédica en Red de Enfermedades Hepáticas y Digestivas \\ (CIBEREHD), Instituto Carlos III, Madrid, Spain. \\ ${ }^{3}$ Liver Cancer Program, Division of Liver Diseases, Mount Sinai School of Medicine, New York, \\ (NY), USA. \\ ${ }^{4}$ Institució Catalana de Recerca i Estudis Avançats, Barcelona, Catalonia, Spain.
}

\begin{abstract}
Unlike most solid tumors, incidence and mortality of hepatocellular carcinoma (HCC) have increased in the US and Europe in the last decade. Most patients are diagnosed at advanced stages, so there is an urgent need for new systemic therapies. Sorafenib, a tyrosine kinase inhibitor (TKI), has demonstrated clinical efficacy in patients with HCC. Studies in patients with lung, breast, or colorectal cancers indicated that the genetic heterogeneity of cancer cells within a tumor affect its response to therapeutics designed to target specific molecules. When tumor progression requires alterations in specific oncogenes (oncogene addiction), drugs that selectively block their products might slow tumor growth. However, no specific oncogene alterations are yet known to be implicated in HCC progression, so it is important to improve our understanding of its molecular pathogenesis. There are currently many clinical trials evaluating TKIs for HCC, including those tested in combination with (e.g., erlotinib) or compared to (e.g., linifanib) sorafenib as a first-line therapy. For patients that do not respond or are intolerant to sorafenib, TKIs such as brivanib, everolimus, and monoclonal antibodies (e.g. ramucirumab) are being tested as second-line therapies. There are early-stage trials investigating the efficacy for up to 60 reagents for HCC. Together, these studies might change the management strategy for HCC, and combination therapies might be developed for patients with advanced HCC. Identification of oncogenes that mediate progression of HCC, and trials that monitor their products as biomarkers, might lead to personalized therapy; reagents that interfere with signaling pathways required for HCC progression might be used to treat selected populations, and thereby maximize the efficacy and cost-benefit.
\end{abstract}

\section{Keywords}

Liver cancer; personalized medicine; sorafenib; targeted therapy; oncogene addiction

\section{Introduction}

Cancer is the second cause of death in the United States (US) ${ }^{1}$. Data from the Centers for Disease Control and Prevention in 2007 estimate that $~ 565,000$ deaths (23.2\% of total) are

Address for correspondence: Josep M Llovet, MD, Professor of Research, HCC Translational Research Lab, BCLC Group, Liver Unit, CIBERehd, Hospital Clínic, IDIBAPS, C/Rosselló 153, 08036-Barcelona, Catalonia, Spain. Phone: +34-93-2279156. 
related to malignant tumors, following death from heart disease $(\sim 616,000 ; 25.4 \%)^{1}$. Mortality from most malignancies has decreased steadily in the last 20 years ${ }^{2}$. However, mortality from liver cancer has increased significantly from 1990 to 2005, by as much as $50 \%$ in men $^{2}$. Studies have reported an increase in liver cancer incidence among Western countries $^{3,4}$, which ultimately impact liver cancer mortality. However, HCC incidence is markedly higher in Asia and Sub-Saharan regions. Epidemiological evidence indicates that the medical and economic burden of liver cancer will increase significantly in Western populations during next decades ${ }^{5}$.

Hepatocellular carcinoma (HCC) is the most common type of primary liver cancer, accounting for more than $85 \%$ of cases worldwide ${ }^{6}$. Chronic liver diseases contribute to most cases of HCC; most frequently viral hepatitis (B and C) and alcohol abuse ${ }^{6}$. Interventions that aim to reduce hepatitis B-related liver disease (antivirals ${ }^{7}$ and vaccination $^{8}$ ) have effectively decreased incidence of HCC. Besides these prophylactic measures, there are not widely accepted chemopreventive strategies to limit development of HCC once cirrhosis is established ${ }^{9}$. Early-stage HCC is frequently asymptomatic, so many patients are diagnosed at intermediate or advanced stages, when therapies are less effective ${ }^{6}$. Surveillance programs were included in clinical practice guidelines, ${ }^{9}$ to increase the number of patients diagnosed at early stages. As a result, around $30 \%$ of patients in Japan are diagnosed with tumors less than $2 \mathrm{~cm}$ in diameter. Nevertheless, in the US less than $20 \%$ of cirrhotic patients who develop HCC have received regular surveillance ${ }^{10}$.

In 2001, the Food and Drug Administration (FDA) approved imatinib for treatment of chronic myeloid leukemia (CML), after a fairly short developmental period. Clinical trials had shown that imatinib induced remission in most patients, based on hematological and cytogenetic evidence. ${ }^{11}$ Imatinib was the first and probably the most successful tyrosine kinase inhibitor (TKI) developed for treatment of cancer; this led to development other targeted therapies in oncology. TKIs were developed for several solid tumors and interest in the molecular pathways of cancer pathogenesis increased, in hopes of finding new therapeutic targets.

The development of TKIs has been important for treatment of liver cancer. In 2007, a Phase 3 randomized controlled trial (RCT) showed that sorafenib, an inhibitor of tyrosine kinases including BRAF, the vascular endothelial growth factor receptor (VEGFR), and plateletderived growth factor receptor (PDGFR), significantly increased survival times of in patients with advanced $\mathrm{HCC}^{12}$. This was the first time a systemic agent was found to increase survival time of patients with HCC; sorafenib is now the standard of care for patients with advanced-stage $\mathrm{HCC}^{13}$. We review the rationale for the use of targeted therapies, focusing on use of TKIs for treatment of HCC and their potential impact on disease management.

\section{Therapeutic Strategies for HCC}

According to the Barcelona Clinic Liver Cancer (BCLC) algorithm ${ }^{13}, 14$, HCC can be classified into 5 stages, based on tumor burden, liver function, and health status. Besides its use in prognosis, this staging system assigns a specific therapeutic strategy to each stage. Recent studies found that the BCLC algorithm provided the best prognostic stratification, compared with other staging proposals ${ }^{15}$. It has been endorsed by the American Association for the Study of Liver Diseases and the European Association for the Study of the Liver ${ }^{9}, 13$ for decision-making in the routine, clinical setting. It also provides researchers with a framework to unify inclusion criteria for clinical trial design and comparison of results.

Following the BCLC algorithm, patients with early-stage disease (BCLC 0-A) receive radical therapies such as surgical resection, liver transplantation, and percutaneous ablation; 
5-year survival rates are $60 \%-70 \%$. Patients with single nodules, without clinically significant portal hypertension, are treated with resection, whereas those with a single nodule less than $5 \mathrm{~cm}$ or 3 nodules less than $3 \mathrm{~cm}$ (Milan criteria) and portal hypertension or liver dysfunction receive liver transplantation ${ }^{16}$. There have been attempts to expand these criteria based on pathology variables, such as number and size of HCC nodules. However, when these expanded criteria have been applied, outcomes are not comparable to those achieved to those of patients stratified based on the Milan criteria ${ }^{17}$. Analyses based on molecular features from the tumor and the cirrhotic adjacent tissue (the tumor microenvironment) might aide in selection of candidates for liver transplantation. Patients with small tumors and contra-indications for surgical therapies are treated by ablative techniques. However, HCC recurs at 5-year cumulative rates of $70 \%$ after resection or ablation $^{18}$.

Patients with intermediate-stage disease (BCLC-B) are candidates for transarterial chemoembolization $\left(\mathrm{TACE}^{19}\right.$ ), which provides loco-regional control of $\mathrm{HCC}$ and increases median survival times by $20-25$ months $^{20,21}$. Improvements in embolization devices, such as drug-eluting beads, have significantly reduced the systemic toxicity associated with conventional TACE ${ }^{22,23}$. Other loco-regional devices being evaluated include transarterial radioembolization with microspheres of Ytrium-90, which is the most promising, based on results from early-stage trials ${ }^{24}$. Patients with advanced-stage HCC (BCLC-C) are candidates to receive sorafenib $(400 \mathrm{mg} \text {, twice daily })^{12}$. Table 1 lists the trials of targeted therapies for advanced HCC that have been registered at www.clinicaltrials.gov. Patients in terminal-stage HCC (BCLC-D) have a median survival time of less than 3 months and should receive supportive care.

\section{Pathogenesis and Targeted Therapies}

High-throughput genomic technologies such as array-based gene expression profiling or parallel sequencing have increased our capacity to analyze human oncogenome ${ }^{25}$. Large numbers of samples can be simultaneously analyzed and compared, and integrative analytical tools have allowed us to associate certain oncogenes with specific tumor types (e.g. $M I T F$ with melanoma ${ }^{26}$, CDK8 with colorectal cancer ${ }^{27}$ ); genomes of lung tumor ${ }^{28}$, glioma $^{29}$, sarcoma $^{30}$, and prostate tumors have been analyzed ${ }^{31}$.

It is important to distinguish between molecular alterations that promote tumor progression and bystander, random events. Theoretically, drugs that prevent tumor progression might stop growth or spread of tumors, whereas those that target bystander defects would not affect tumor development. Studies in animal models have provided functional confirmation that specific alterations in oncogenes and tumor suppressors are required for tumor progression, ${ }^{32,} 33$ including $\mathrm{HCC}^{34,35}$.

Unlike other solid tumors ${ }^{36}$, the specific sequence of genetic events that mediate hepatocarcinogenesis are not known. HCC usually progresses from chronic hepatitis, to cirrhosis, to dysplastic nodules (low- and high-grade), to malignant tumors. Studies have analyzed the genetic features associated with each stage — especially the transition from high-grade dysplastic nodules to early-stage HCC. Gene expression studies identified MYC and TLRS as important mediators of malignancy ${ }^{37,38}$. Nevertheless, specific genetic variants have not been associated with HCC.

\section{Signal Transduction}

HCCs have been categorized into 3 subgroups, based on gene expression patterns. ${ }^{39-41}$ One subgroup is characterized by altered expression of genes that regulate proliferation or the cell cycle, such as mammalian target of rapamycin $(m T O R)^{42}$, insulin-like growth factor 
$(I G F)^{43}$, and $R A S ;^{44}$ and also includes gene signatures previously associated with poor outcome (e.g. proliferation ${ }^{45}, \mathrm{G}^{46}$, cluster $\mathrm{A}^{47}$ ). A second subgroup is characterized by activation of the WNT signaling pathway, which is involved in liver development and $\mathrm{HCC}^{48}$. The third subgroup is not clearly defined but includes altered expression of genes involved in interferon (IFN) signaling and inflammation. These subgroups can be further subdivided based on dominant features, such as upregulation of AKT-MYC signaling ${ }^{49}$, probably via oncogene activation. These signaling pathways are likely to be important for tumor progression, making them good candidates for selective blockade.

Gene expression profiling studies have also been performed on adjacent, non-tumor, cirrhotic tissue (the tumor microenvironment), ${ }^{50-52}$ to identify patterns that might be used in prognosis. The tumor microenvironment can affect intra-hepatic dissemination, development of de novo tumors, and progression of liver dysfunction. The expression of 186 genes from adjacent, cirrhotic tissue (including genes that encoded epidermal growth factor (EGF), interleukin (IL)-6, and components of the transcription factor NF- $\mathrm{kB}$ ) correlated with survival times of patients with early-stage HCC who were treated by surgical resection ${ }^{51}$. This gene expression signature predicted HCC development in 216 patients with HCVrelated cirrhosis who were followed in a surveillance program for approximately 10 years ${ }^{53}$. Accurate prognosis for patients with $\mathrm{HCC}$ will require combination of clinical variables (the BCLC algorithm) and molecular data from the tumor and adjacent, cirrhotic tissue ${ }^{40,54}$. A recent study showed that an integrated approach increased the accuracy of prognosis, compared with just considering clinical and/or pathological variables. 55

Signal transduction pathways are fast-operating systems that regulate gene expression and induce context-specific cellular responses ${ }^{56}$. Some pathways share a common structure (e.g., EGFR, IGFR, MET), in which a receptor with tyrosine kinase activity is phosphorylated upon binding to a specific extracellular ligand. Activated receptor tyrosine kinases (RTKs) signal through second messengers (e.g., RAS, AKT) to regulate cell processes and gene expression patterns. RTKs are cell-surface receptors with high affinities for specific ligands. They comprise an extracellular, $\mathrm{N}$-terminal region that binds ligands and a conserved, $\mathrm{C}$ terminal region that autophosphorylates to create binding sites for $\mathrm{SH} 2$ and other phosphotyrosine-binding proteins, such as Src. These proteins recruit additional adaptors that propagate signals. In cancer cells, the C-terminal domains of some RTKs contain mutations that allow their constitutive activation (even in the absence of ligand) and signaling, such as EGFR mutations in lung cancer cells ${ }^{57}$. TKI prevent autophosphorylation of RTK, through either competitive binding with ATP or allosteric inhibition, to interrupt signal transduction. In other pathways, such as Notch signaling ${ }^{58}$, receptor activation requires cell-to-cell contact, which induces cleavage of the receptor and its translocation to the nucleus. Several signaling pathways (WNT- $\beta$-catenin, RAS-MAPK, AKT-mTOR, EGFR, IGFR, HGF-MET) are activated in HCC (for reviews, see ${ }^{59}$ ). Interestingly, specific signaling pathways are activated in the different subclasses of $\mathrm{HCC}^{39}$. Most TKI being developed for treatment of HCC target different factors in several of these pathways (Table $1)$.

Signals and processes in the tumor microenvironment contribute to tumor growth and metastasis, such as through neo-angiogenesis. Growth and sprouting of intratumoral blood vessel are tightly regulated and required for $\mathrm{HCC}$ progression; ${ }^{60}$ angiogenesis occurs in cirrhotic tissue and contributes to development of $\mathrm{HCC}^{61}$. Angiogenesis also promotes portal hypertension and progression of liver dysfunction. TKIs have therefore been developed to block this process and are being tested in clinical trials (Table 1). Strategies have been developed to block VEGFR alone (cediranib) or in combination with other angiogenic receptors, such as PDGFR (sorafenib, sunitinib, linifanib, pazopanib) or the fibroblast growth factor receptor (FGFR; brivanib). A monoclonal antibody against VEGF- 
A (bevacizumab) also blocks angiogenic signals from tumor microenvironment. Blockade of angiogenic receptors with TKIs has anti-fibrotic activity (sunitinib, imatinib) and reduces the risk of HCC in experimental models ${ }^{62,63}$.

Activation of EGF signaling in cirrhotic tissue has also been associated with HCC development. Gene expression data also indicates its involvement in reduced survival time after surgery. ${ }^{51},{ }^{64}$ The EGF TKI gefitinib significantly reduced the rate of HCC development in rats ${ }^{65}$. Results from a Phase 3 trial—sorafenib vs placebo as adjuvant therapy after curative treatment-(STORM) will provide more information about whether inhibiting kinase activity in the tumor microenvironment reduces the risk of $\mathrm{HCC}$ recurrence.

\section{Oncogene Addiction}

Proliferation and survival of some cancer cells requires activation of specific oncogenes and inactivation of specific tumor suppressors, called oncogene addiction ${ }^{66}$. It was originally described when researchers found that malignant phenotypes of some tumors required activation of certain oncogenes; ${ }^{67}$ not all genetic variants associated with cancer cells are required for their proliferation and survival. Osteosarcomas require MYC - tumor growth slows when MYC is inactivated ${ }^{68}$. Pathogenesis of CML requires the kinase $\mathrm{ABL}$, which is inhibited by imatinib - this drug prevents CML progression and prolongs survival times of patients ${ }^{11}$. Mutations in EGFR are required for growth of some types of lung tumors, which respond to the kinase inhibitor gefitinib. Increased expression of HER2/neu (via gene amplification) is required for growth of some gastric and breast tumors, which respond to transtuzumab, a monoclonal antibody $(\mathrm{mAb})$ against this receptor ${ }^{69,70}$. Some types of melanoma require BRAF1 signaling, and have been reported to respond to inhibitors this signaling molecule ${ }^{71}$. Malignancy of cancer cells can also require (or they are addicted to) other networks that support tumor growth or progression but are not oncogenic, such as protein degradation or mitotic stress-this is called 'non-oncogene addiction' ${ }^{72}$.

It might therefore be possible to treat cancer patients by targeting molecules that are required for progression of their particular tumor - in personalized medicine, medical interventions are designed based on genetic features of the tumor and patient ${ }^{73}$. Before these types of strategies can be developed for patients with $\mathrm{HCC}$, however, we need to identify and validate molecules required for $\mathrm{HCC}$ growth or progression and develop specific inhibitors of these factors. For example, WNT and RAS are activated in $25 \%$ and $\sim 50 \%$ of $\mathrm{HCCs}$, respectively, but specific inhibitors have not entered trials for HCC. ${ }^{72}$ HCCs have significant amounts of genomic heterogeneity and multiple oncogenic pathways can be activated. Studies are needed of large numbers of tumor specimens, to identify the best therapeutic targets.

The National Cancer Institute created the Cancer Target Discovery and Development Network $^{74}$. Its mission is to analyze genotypes out of different tumor types and identify oncogene pathways required for progression of specific tumors, so that small molecules can be developed to target them. In addition, there are trials to evaluate drugs that target activated oncogenic pathways in specific tumors, such as the BATTLE trial for lung cancer or the ToGA trial for gastric cancers that overexpress HER2/neu ${ }^{70}$.

\section{TKIs and HCC}

The mainstreams of molecular therapy are currently monoclonal antibodies (mAB) and TKI. What are the differences between inhibiting a kinase with a small-molecule TKI vs a mAb? $\mathrm{mAbs}$ are larger molecules that cannot cross the blood-brain barrier and require intravenous administration. Their half-life is longer than that of TKI, what allows for weekly dosing. 
Pharmacokinetic studies have shown that plasma levels of TKI can vary among patients, probably because they are administered orally. MAbs are unable to pass through the cell membrane, which limits their potential targets to surface or secreted molecules. TKI are less specific than mAbs, increasing their off-target effects and toxicities. However, this also allows for simultaneous inhibition of different kinases; sorafenib inhibits several kinases that may be active in HCC. Although mAbs are specific for a single molecule, they can also activate anti-tumor immune responses. mAbs have higher rates of FDA approval (18\%$29 \%^{77}$ ) for patients with cancer than small molecules $\left(5 \%-8 \%{ }^{78}\right)$, but are more expensive.

\section{Sorafenib for HCC}

Sorafenib was approved for hepatocellular carcinoma in $2007^{79}$, and it is the standard of care for patients in advanced-stage HCC (BCLC-C). Sorafenib therapy should be given to the control group in trials of new reagents in first line for HCC patients at this stage ${ }^{13}$. In the Sorafenib Hepatocellular Carcinoma Assessment Randomized Protocol-SHARP study, ${ }^{12}$ a double-blind, RCT with a primary endpoint of overall survival, ${ }^{80}$ sorafenib significantly increased survival times of patients with HCC, from 7.9 to 10.7 months, with a manageable profile of side effects.

Sorafenib's anti-tumor efficacy was mainly achieved by delaying time to radiologic progression (from 2.8 to 5.5 months). Objective responses, according to response evaluation criteria in solid tumors (RECIST) ${ }^{81}$ criteria, were low (<3\%). Nonetheless, there are new ways of assessing response rate and progression (modified RECIST) being developed for cancer trials ${ }^{82}$. The magnitude of sorafenib's effect is within range of other TKIs approved for patients with solid tumors (Table 2). Since most patients in this trial were from Europe or the US (primarily HCV-related disease), a parallel trial was conducted in the Asian-Pacific region (primarily HBV-related disease). Results of this trial validate the magnitude of the benefit of sorafenib compared to placebo (hazard ratio of 0.68 ), ${ }^{83}$ although the absolute difference in survival times was smaller than in the SHARP study (from 4.2 to 6.5 months). Patients with more advanced-stage $\mathrm{HCC}$ were selected for the Asian trial, which might account for this difference.

Sorafenib blocks different signaling pathways, including those that regulate cell proliferation (via RAS-MAPK) and angiogenesis (via VEGFR and PDGFR). It is therefore a challenge to determine which specific effects of sorafenib slow HCC progression. In a phase 2 trial of sorafenib, patients with tumors with high levels of phosphorylated ERK (a downstream molecular of RAS) had a significantly greater rate of survival than with low phosphorylated ERK levels ${ }^{84}$. However, these findings were not validated in the phase 3 trial. A study has associated response to sorafenib with levels of the kinase c-KIT and heptocyte growth factor (HGF) (a non-significant trend, data not published), but there are no strong biomarkers of response. A Canadian study found that sorafenib is cost-effective, compared with the supportive care for $\mathrm{HCC}^{85}$, but larger efforts are still needed to precisely evaluate the economic impact of this drug.

Sorafenib is contraindicated for patients with severe cardiovascular disease (heart failure with an ejection fraction less that 50\%, severe intermittent claudication, unstable angina, myocardial infarction, or stroke in the previous 6 months), performance status $>2$, clinically significant portal hypertension (gastrointestinal bleeding in the previous month or varices with red wale marks), or liver dysfunction (Child-Pugh>B7). Decompensated diabetes mellitus or arterial hypertension should be treated and controlled before treatment starts.

Patients treated with sorafenib should be monitored every 4-6 weeks for toxicities-patients should be educated about possible side effects before they start therapy. Skin reactions are among the most frequent, occurring in $20 \%-40 \%$ of patients, and include hand and foot 
reactions, dry skin, pruritus, rash or desquamation, alopecia, and psoriasiform eruptionsthese are rarely severe enough to require dose reduction or temporary treatment withdrawal. Gastrointestinal toxicities occur among 20\%-30\% of patients with HCC that receive sorafenib, including severe diarrhea in $10 \%$ of patients. Other potential side effects include anorexia, stomatitis, nausea or vomiting, voice changes, fatigue, weight loss, and hypertension.

Following the successful results of the SHARP trial, there has been interest in developing new targeted therapies for HCC-there are now more than 50 reagents that are being tested in almost 200 trials (see Table 1). Most of these agents are designed to inhibit angiogenesis, an important process in HCC pathogenesis and progression ${ }^{60}$. There are 65 registered trials testing sorafenib (alone or in combination with other reagents), in phases $1-4^{86}$.

Bevacizumab is the second-most frequently tested drug, followed by erlotinib (a TKI of EGFR), everolimus (inhibits the serine/threonine kinase mTOR), and brivanib (inhibits FGFR). There are 6 kinase inhibitors being tested in phase 3 pivotal trials for regulatory approval, to change the standard of care (see Table 3). These trials include first-line (sorafenib, erlotinib, brivanib, and linifanib), second-line (everolimus and brivanib), and adjuvant therapy, after resection or ablation (sorafenib), or prevention of recurrence after liver transplantation (rapamycin). A phase 3 trial evaluating sunitinib (anti-PDGFR) vs sorafenib as a first-line therapy for HCC was prematurely stopped because of lack of efficacy and significant adverse events among patients given sunitinib. There were 2 previous phase 2 trials of sunitinib that reported that $5 \%-10 \%$ of patients died from treatment-related causes 87,88 .

An important goal of HCC research and therapy is to prevent tumor recurrence-almost $70 \%$ of patients treated with resection or local ablation have recurrence of HCC within 5 years ${ }^{18}$. Recurrence could result sfrom intra-hepatic metastases that remain after incomplete treatment of the primary tumor or through formation of new tumors, caused by the persistence of the carcinogenic field present in cirrhotic liver. These types of recurrence are roughly distinguished based on the time of appearance (before or after 2 years following resection or ablation ${ }^{89}$ ), although the difference is arbitrary and varies based on the stage of the tumor removed. The molecular features of each recurrent tumor type are likely to differ. Sorafenib is being tested as an adjuvant therapy in the STORM trial-the largest trial ever conducted on patients with HCC (1100 patients).

\section{Reagents in Development}

There are 16 reported phase 2 and 3 trials analyzing TKI in patients with HCC (Table $4^{12,83,84,87,88,90-97}$ ). Unfortunately, the patient populations included in most of the phase 2 trials are heterogeneous, in terms of underlying liver disease and staging systems; the studies also vary in primary endpoints (response rate, progression-free survival, overall survival) and measures of tumor response (RECIST or World Health Organization criteria). Overall survival reported in these trials ranges from $5^{97}$ to $15.7{ }^{96}$ months. The variations in trial design and results make it a challenge to identify determinants of efficacy and compare findings with previous studies-it is therefore important to unify criteria for trial design for HCC. This task was undertaken by a group of experts that proposed a set of guidelines for trial design, providing the scientific community with a consensus framework ${ }^{13}$. These recommendations were based on the fact that $\mathrm{HCC}$ has a different pattern of development from other solid tumors, because many patients also have cirrhosis. Patient mortality results from cancer and liver dysfunction. To accurately determine the anti-tumor activity of a reagent, patients and endpoints must be carefully selected, to discern between cancer and non-cancer related events. The low objective response, based on RECIST, achieved in the SHARP trial indicates the need for better methods to evaluate tumor responses to TKIs. The 
recently proposed modified RECIST criteria $^{82}$ might improve radiological assessment of tumor response.

Many agents have been evaluated in single-arm, phase 2 studies of patients with advanced HCC (Table 4). Patients given brivanib as a first-and second-line therapy have median survival times of 10 and 9.8 , respectively ${ }^{98}$. The safety profile of the drug was manageable, and it is now under evaluation in phase 3 (Table 3). In 2 single-arm studies of erlotinib, ${ }^{93,}, 95$ median survival times were 13 and 6.2 months, with response rates below 10\%; erlotinib is also in phase 3 trials for advanced HCC. Two independent phase 2 trials showed anti-tumor activities of sunitinib ${ }^{87,88}$, but then preliminary data from a phase $3 \mathrm{RCT}$, indicating toxicity and lack of efficacy, ended development of this reagent for HCC. Bevacizumab was evaluated in phase 2 trials and stabilized disease in $30 \%$ of patients ${ }^{99}$. Lapatinib, a TKI of EGFR and Her2, had marginal efficacy in patients with HCC - their median survival time was 6.3 months; ${ }^{94}$ patients who developed a rash, an effect attributable to EGFR blockage, had longer survival times. The kinase mTOR is activated in HCC and everolimus had antitumor activity in experimental models of this cancer, ${ }^{42}$ leading to its testing in phase 2 and 3 trials. The mTOR inhibitor rapamycin is also being tested, in patients with HCC that received liver transplants. It can also prevent organ rejection in this setting. Pre-clinical data indicated anti-tumor activity of the anti-angiogenic reagents cediranib ${ }^{100}$ and vandetanib ${ }^{101}$, leading to their evaluation in phase 2 trials. A randomized phase 2 trial evaluated the combination of doxorubicin and sorafenib vs doxorubicin alone found that overall survival in group given the combination therapy was significantly higher that in the doxorubicin arm, 102 although $60 \%$ of all patients had grade- 3 or -4 toxicities. A single-arm, phase 2 study analyzed the potential synergistic effects of erlotinib and bevacizumab and reported overall survival time of 15.7 months and a response rate of $25 \% 96$.

\section{Clinical Benefits and Cost-Effectiveness}

The magnitude of effects of oncologic drugs is estimated based on the clinical endpoints used to measure efficacy and absolute (e.g. increased time of survival) and relative (e.g. the hazard ratio) differences measured, compared with controls. Regulatory agencies use different endpoints in deciding whether to approve reagents for treatment of cancer patients, including overall survival, progression-free survival, and time to progression (Table 2). The hazard ratio for FDA approval of sunitinib was 0.41 in patients with advanced renal cancer and for erlotinib was 0.81 in patients with metastatic pancreatic cancer. Absolute increases in clinical benefits should also be considered. Erlotinib was found to increase survival times of patients with pancreatic cancer by 2 weeks; ${ }^{103}$ this result was statistically significant, but not necessarily clinically relevant. In fact, the 2009 European Society for Medical Oncology clinical recommendations for pancreatic cancer management discouraged the use of erlotinib because of the modest gain in survival time ${ }^{104}$. However, in a broader perspective, cumulative gains of relatively small effects can produce important clinical benefits. For example, survival times of patients with colorectal cancer (CRC) increased from 1990 to 2005 (Figure 1), because sequential introduction of different systemic agents improved median survival times from $\sim 5$ months with best supportive care up to $\sim 20$ when patients were given the combination of irinotecan, 5-fluoruoracil, leucovorin, and bevacizumab. This increase in life expectancy by $\sim 15$ months, achieved over a 15 -year period of research, might have been aided by other factors, such as optimized nutrition and better antibiotics.

The costs of managing cancer patients have significantly increased in the last decade, which affects science and society ${ }^{105}$. There are several variables to consider in weighing economic cost vs clinical benefit of therapies; these are considered in cost-benefit, cost-effectiveness, and cost-utility analyses (reviewed in ${ }^{106}$ ). In cost-utility analysis, benefits are measured in terms of quality-adjusted life years (QALY), which allows for comparisons between 
different medical interventions. A commonly used threshold, which was generated in the 1980s for a given intervention to be considered as cost-effective, was \$50,000/QALY ${ }^{107}$, but recent studies recommend increasing the threshold to $\$ 300,000 ;{ }^{108,109}$ there is, however, no empirical evidence to support any particular threshold. A prospective analysis showed that the incremental increase in cost effectiveness of the EGFR inhibitor cetuximab, compared with best supportive care, for unselected patients with advanced CRC was greatest when cetuximab therapy was limited to patients with tumors that expressed wild-type KRAS $^{110}$. In addition to scientific reasons, there are also economic reasons for selection of specific populations of patients for targeted therapies.

\section{Improving Efficacy of Treatment}

Imatinib was developed using rational drug design ${ }^{111}$ — the development of therapeutic reagents based on specific biologic targets. Screens of chemical libraries for inhibitors of BCR-ABL activity identified a precursor of imatinib. Since its approval for treatment of CML in 2001, several other TKI have been approved for treatment of patients with solid tumors, including non-small cell lung cancer (NSCLC), pancreatic cancer, breast, CRC and HCC (Table 2). Most of these were approved based on data from phase 3 RCT that included solid clinical endpoints. However, some drugs have been approved for cancer therapy based on "a surrogate, or substitute endpoint reasonable likely to predict clinical benefit" "112, which is called accelerated approval. This was the case for the EGFR inhibitor gefinitib, which was approved in 2003 for treatment of NSCLC, based on an objective response of $10.6 \%$ in a phase 2 trial of 142 patients $^{113}$. However, the FDA stated that the company that manufactured this drug still needed to conduct studies to correlate the observed tumor shrinkage with longer survival time. Unexpectedly, a phase 3 RCT of 1962 patients with NSCLC did not find that gefitinib increased survival time, ${ }^{114}$ although data indicated that a subgroup of patients were more likely to benefit - those with activating mutations in EGFR or those that overexpressed this receptor $57,115,116$. An additional trial then found that patients with NSCLC who had activating mutations in EGFR had longer times of progression-free survival (hazard ratio of 0.3) after receiving gefitinib that patients who received conventional chemotherapy ${ }^{117}$.

A similar situation occurred in testing cetuximab, a mAb against EGFR, in patients with CRC. In 2007, a second-line RCT of 572 patients with CRC whose tumors overexpressed EGFR found that cetuximab increased overall survival (hazard ratio 0.77, Figure 1) ${ }^{118}$. Data from 394 patients from this cohort indicated that analysis of KRAS mutation could be used to identify those most likely to respond to cetuximab ${ }^{119}$ —patients whose tumors had mutated KRAS didn't responde to cetuximab (hazard ratio of 0.98) when compared to those with wild-type KRAS (hazard ratio of 0.55, Figure 1). Testing patients for KRAS mutations before treatment with EGFR inhibitors is now an American Association for Clinical Oncology provisional clinical opinion ${ }^{120}$. Knowledge about how specific genetic alterations affect tumor progression is important for maximizing patients' response to targeted therapies. However, little is known about specific oncogenic mutations required for growth and progression of HCC, so patients cannot yet be selected for trials or therapy based on genetic features.

Findings from research into the pathogenesis and treatment of other solid tumors, such as breast or colorectal cancer, might someday be applied to HCC, such as molecular classification of tumors, prognosis based on genomic factors, and predicted response to therapy based on knowledge of oncogene addiction (see Figure 2). It is important to increase our understanding of mechanisms of tumorigenesis and development, and continue our research into checkpoint inactivation (e.g. via mutations in p53), cell immortalization (e.g. via inactivation of TERT), and neo-angiogenesis (e.g. via activation of VEGF, angiopoetin, 
and $\mathrm{FGF}^{121}$ ). Patients with advanced HCC are treated with sorafenib, but selective agents that block specific factors required for HCC progression would improve its efficacy. However, safety is a concern, because combinations of TKI might be toxic for patients with cirrhosis. It is also important to determine which factors are required for growth and development of the specific subclasses of HCC, as well as biomarkers of response, to individualize therapeutic regimens. International, high-throughput sequencing efforts (e.g. the Cancer Genome Atlas, The International Sequencing Consortium) and research networks (HEPTROMIC, www.heptromic.eu) should contribute to this effort.

\section{Acknowledgments}

Grant Support: JML has grants from National Institute of Health -NIDDK 1R01DK076986-01, European Comission-FP7 grant (HEPTROMIC, 2010); National Institute of Health (Spain) grant I+D Program (SAF-2007-61898; SAF-2010) and Samuel Waxman Cancer Research Foundation.

\section{Abbreviations}

$\begin{array}{ll}\text { BCLC } & \text { Barcelona Clinic Liver Cancer } \\ \text { CML } & \text { chronic myeloid leukemia } \\ \text { CRC } & \text { Colorectal cancer } \\ \text { CUA } & \text { Cost-utility analysis } \\ \text { FDA } & \text { Food and Drug Administration } \\ \text { GIST } & \text { Gastrointestinal stromal tumor } \\ \text { HBV } & \text { hepatitis B virus } \\ \text { HCV } & \text { hepatitis C virus } \\ \text { HCC } & \text { hepatocellular carcinoma } \\ \text { HR } & \text { hazard ratio } \\ \text { mAbs } & \text { Monoclonal antibodies } \\ \text { NSCLC } & \text { non-small cell lung cancer } \\ \text { OA } & \text { Oncogene addiction } \\ \text { QALY } & \text { Quality-adjusted life year } \\ \text { RCT } & \text { randomized controlled trial } \\ \text { TACE } & \text { transarterial chemoembolization } \\ \text { TKI } & \text { tyrosine kinase inhibitor }\end{array}$

\section{REFERENCES}

1. http://www.cdc.gov/nchs/.

2. Jemal A, Siegel R, Ward E, Hao Y, Xu J, Thun MJ. Cancer statistics, 2009. CA Cancer J Clin. 2009; 59:225-249. [PubMed: 19474385]

3. El-Serag HB. Hepatocellular carcinoma: recent trends in the United States. Gastroenterology. 2004; 127:S27-S34. [PubMed: 15508094]

4. Fattovich G, Stroffolini T, Zagni I, Donato F. Hepatocellular carcinoma in cirrhosis: incidence and risk factors. Gastroenterology. 2004; 127:S35-S50. [PubMed: 15508101]

5. El-Serag HB, Rudolph KL. Hepatocellular carcinoma: epidemiology and molecular carcinogenesis. Gastroenterology. 2007; 132:2557-2576. [PubMed: 17570226] 
6. Llovet JM, Burroughs A, Bruix J. Hepatocellular carcinoma. Lancet. 2003; 362:1907-1917. [PubMed: 14667750]

7. Liaw YF, Sung JJ, Chow WC, et al. Lamivudine for patients with chronic hepatitis B and advanced liver disease. N Engl J Med. 2004; 351:1521-1531. [PubMed: 15470215]

8. Chang MH, Chen CJ, Lai MS, et al. Universal hepatitis B vaccination in Taiwan and the incidence of hepatocellular carcinoma in children. Taiwan Childhood Hepatoma Study Group. N Engl J Med. 1997; 336:1855-1859. [PubMed: 9197213]

9. Bruix J, Sherman M. Management of hepatocellular carcinoma: An Update. Amercian Association for the Study of Liver Diseases. $2010 \mathrm{http}: / /$ wwwaasldorg/practiceguidelines.

10. Davila JA, Morgan RO, Richardson PA, Du XL, McGlynn KA, El-Serag HB. Use of surveillance for hepatocellular carcinoma among patients with cirrhosis in the United States. Hepatology. 2010; 52:132-141. [PubMed: 20578139]

11. Sawyers CL. Shifting paradigms: the seeds of oncogene addiction. Nat Med. 2009; 15:1158-1161. [PubMed: 19812578]

12. Llovet JM, Ricci S, Mazzaferro V, et al. Sorafenib in advanced hepatocellular carcinoma. N Engl J Med. 2008; 359:378-390. [PubMed: 18650514]

13. Llovet JM, Di Bisceglie AM, Bruix J, et al. Design and endpoints of clinical trials in hepatocellular carcinoma. J Natl Cancer Inst. 2008; 100:698-711. [PubMed: 18477802]

14. Llovet JM, Bru C, Bruix J. Prognosis of hepatocellular carcinoma: the BCLC staging classification. Semin Liver Dis. 1999; 19:329-338. [PubMed: 10518312]

15. Marrero JA, Fontana RJ, Barrat A, et al. Prognosis of hepatocellular carcinoma: comparison of 7 staging systems in an American cohort. Hepatology. 2005; 41:707-716. [PubMed: 15795889]

16. Mazzaferro V, Regalia E, Doci R, et al. Liver transplantation for the treatment of small hepatocellular carcinomas in patients with cirrhosis. N Engl J Med. 1996; 334:693-699. [PubMed: 8594428]

17. Mazzaferro V, Llovet JM, Miceli R, et al. Predicting survival after liver transplantation in patients with hepatocellular carcinoma beyond the Milan criteria: a retrospective, exploratory analysis. Lancet Oncol. 2009; 10:35-43. [PubMed: 19058754]

18. Llovet JM, Schwartz M, Mazzaferro V. Resection and liver transplantation for hepatocellular carcinoma. Semin Liver Dis. 2005; 25:181-200. [PubMed: 15918147]

19. Lencioni R. Loco-regional treatment of hepatocellular carcinoma. Hepatology. 2010

20. Llovet JM, Bruix J. Systematic review of randomized trials for unresectable hepatocellular carcinoma: Chemoembolization improves survival. Hepatology. 2003; 37:429-442. [PubMed: 12540794]

21. Llovet JM, Real MI, Montana X, et al. Arterial embolisation or chemoembolisation versus symptomatic treatment in patients with unresectable hepatocellular carcinoma: a randomised controlled trial. Lancet. 2002; 359:1734-1739. [PubMed: 12049862]

22. Lammer J, Malagari K, Vogl T, et al. Prospective randomized study of doxorubicin-eluting-bead embolization in the treatment of hepatocellular carcinoma: results of the PRECISION V study. Cardiovasc Intervent Radiol. 2010; 33:41-52. [PubMed: 19908093]

23. Varela M, Real MI, Burrel M, et al. Chemoembolization of hepatocellular carcinoma with drug eluting beads: efficacy and doxorubicin pharmacokinetics. J Hepatol. 2007; 46:474-481. [PubMed: 17239480]

24. Salem R, Lewandowski RJ, Mulcahy MF, et al. Radioembolization for hepatocellular carcinoma using Yttrium-90 microspheres: a comprehensive report of long-term outcomes. Gastroenterology. 2010; 138:52-64. [PubMed: 19766639]

25. Kulasingam V, Pavlou MP, Diamandis EP. Integrating high-throughput technologies in the quest for effective biomarkers for ovarian cancer. Nat Rev Cancer. 2010; 10:371-378. [PubMed: 20383179]

26. Garraway LA, Widlund HR, Rubin MA, et al. Integrative genomic analyses identify MITF as a lineage survival oncogene amplified in malignant melanoma. Nature. 2005; 436:117-122. [PubMed: 16001072]

27. Firestein R, Bass AJ, Kim SY, et al. CDK8 is a colorectal cancer oncogene that regulates betacatenin activity. Nature. 2008; 455:547-551. [PubMed: 18794900] 
28. Weir BA, Woo MS, Getz G, et al. Characterizing the cancer genome in lung adenocarcinoma. Nature. 2007; 450:893-898. [PubMed: 17982442]

29. Verhaak RG, Hoadley KA, Purdom E, et al. Integrated genomic analysis identifies clinically relevant subtypes of glioblastoma characterized by abnormalities in PDGFRA, IDH1, EGFR, and NF1. Cancer Cell. 2010; 17:98-110. [PubMed: 20129251]

30. Barretina J, Taylor BS, Banerji S, et al. Subtype-specific genomic alterations define new targets for soft-tissue sarcoma therapy. 2010

31. Taylor BS, Schultz N, Hieronymus H, et al. Integrative genomic profiling of human prostate cancer. Cancer Cell. 2010; 18:11-22. [PubMed: 20579941]

32. Zender L, Villanueva A, Tovar V, Sia D, Chiang DY, Llovet JM. Cancer gene discovery in hepatocellular carcinoma. J Hepatol. 2010; 52:921-929. [PubMed: 20385424]

33. Frese KK, Tuveson DA. Maximizing mouse cancer models. Nat Rev Cancer. 2007; 7:645-658. [PubMed: 17687385]

34. Zender L, Spector MS, Xue W, et al. Identification and validation of oncogenes in liver cancer using an integrative oncogenomic approach. Cell. 2006; 125:1253-1267. [PubMed: 16814713]

35. Zender L, Xue W, Zuber J, et al. An oncogenomics-based in vivo RNAi screen identifies tumor suppressors in liver cancer. Cell. 2008; 135:852-864. [PubMed: 19012953]

36. Purnak T, Ozaslan E, Efe C. Molecular basis of colorectal cancer. N Engl J Med. 2010; 362:1246. author reply -7. [PubMed: 20364461]

37. Kaposi-Novak P, Libbrecht L, Woo HG, et al. Central role of c-Myc during malignant conversion in human hepatocarcinogenesis. Cancer Res. 2009; 69:2775-2782. [PubMed: 19276364]

38. Wurmbach E, Chen YB, Khitrov G, et al. Genome-wide molecular profiles of HCV-induced dysplasia and hepatocellular carcinoma. Hepatology. 2007; 45:938-947. [PubMed: 17393520]

39. Hoshida Y, Toffanin S, Lachenmayer A, Villanueva A, Minguez B, Llovet JM. Molecular classification and novel targets in hepatocellular carcinoma: recent advancements. Semin Liver Dis. 2010; 30:35-51. [PubMed: 20175032]

40. Villanueva A, Hoshida Y, Toffanin S, et al. New strategies in hepatocellular carcinoma: genomic prognostic markers. Clin Cancer Res. 2010; 16:4688-4694. [PubMed: 20713493]

41. Villanueva A, Toffanin S, Llovet JM. Linking molecular classification of hepatocellular carcinoma and personalized medicine: preliminary steps. Curr Opin Oncol. 2008; 20:444-453. [PubMed: 18525342]

42. Villanueva A, Chiang DY, Newell P, et al. Pivotal role of mTOR signaling in hepatocellular carcinoma. Gastroenterology. 2008; 135:1972-1983. 83, e1-e11. [PubMed: 18929564]

43. Tovar V, Alsinet C, Villanueva A, et al. IGF activation in a molecular subclass of hepatocellular carcinoma and pre-clinical efficacy of IGF-1R blockage. J Hepatol. 2010; 52:550-559. [PubMed: 20206398]

44. Newell P, Toffanin S, Villanueva A, et al. Ras pathway activation in hepatocellular carcinoma and anti-tumoral effect of combined sorafenib and rapamycin in vivo. J Hepatol. 2009; 51:725-733. [PubMed: 19665249]

45. Chiang DY, Villanueva A, Hoshida Y, et al. Focal gains of VEGFA and molecular classification of hepatocellular carcinoma. Cancer Res. 2008; 68:6779-6788. [PubMed: 18701503]

46. Boyault S, Rickman DS, de Reynies A, et al. Transcriptome classification of HCC is related to gene alterations and to new therapeutic targets. Hepatology. 2007; 45:42-52. [PubMed: 17187432]

47. Lee JS, Chu IS, Heo J, et al. Classification and prediction of survival in hepatocellular carcinoma by gene expression profiling. Hepatology. 2004; 40:667-676. [PubMed: 15349906]

48. Thompson MD, Monga SP. WNT/beta-catenin signaling in liver health and disease. Hepatology. 2007; 45:1298-1305. [PubMed: 17464972]

49. Hoshida Y, Nijman SM, Kobayashi M, et al. Integrative transcriptome analysis reveals common molecular subclasses of human hepatocellular carcinoma. Cancer Res. 2009; 69:7385-7392. [PubMed: 19723656]

50. Budhu A, Forgues M, Ye QH, et al. Prediction of venous metastases, recurrence, and prognosis in hepatocellular carcinoma based on a unique immune response signature of the liver microenvironment. Cancer Cell. 2006; 10:99-111. [PubMed: 16904609] 
51. Hoshida Y, Villanueva A, Kobayashi M, et al. Gene expression in fixed tissues and outcome in hepatocellular carcinoma. N Engl J Med. 2008; 359:1995-2004. [PubMed: 18923165]

52. Okamoto M, Utsunomiya T, Wakiyama S, et al. Specific gene-expression profiles of noncancerous liver tissue predict the risk for multicentric occurrence of hepatocellular carcinoma in hepatitis $\mathrm{C}$ virus-positive patients. Ann Surg Oncol. 2006; 13:947-954. [PubMed: 16788756]

53. Hoshida Y, Villanueva A, Sangiovanni A, et al. Gene Expression signature predictis outcome of liver cirrhosis. Hepatology. 2009; 50:312A. (abstract).

54. Villanueva A, Minguez B, Forner A, Reig M, Llovet JM. Hepatocellular carcinoma: novel molecular approaches for diagnosis, prognosis, and therapy. Annu Rev Med. 2010; 61:317-328. [PubMed: 20059340]

55. Villanueva A, Hoshida Y, Battiston C, et al. Combining clinical, pathology, and gene expression data to predict recurrence in hepatocellular carcinoma. Gastroenterology. 2011

56. Kiel C, Yus E, Serrano L. Engineering signal transduction pathways. Cell. 2010; 140:33-47. [PubMed: 20085704]

57. Paez JG, Janne PA, Lee JC, et al. EGFR mutations in lung cancer: correlation with clinical response to gefitinib therapy. Science. 2004; 304:1497-1500. [PubMed: 15118125]

58. Radtke F, Raj K. The role of Notch in tumorigenesis: oncogene or tumour suppressor? Nat Rev Cancer. 2003; 3:756-767. [PubMed: 14570040]

59. Villanueva A, Newell P, Chiang DY, Friedman SL, Llovet JM. Genomics and signaling pathways in hepatocellular carcinoma. Semin Liver Dis. 2007; 27:55-76. [PubMed: 17295177]

60. Semela D, Dufour JF. Angiogenesis and hepatocellular carcinoma. J Hepatol. 2004; 41:864-880. [PubMed: 15519663]

61. Fernandez M, Semela D, Bruix J, Colle I, Pinzani M, Bosch J. Angiogenesis in liver disease. J Hepatol. 2009; 50:604-620. [PubMed: 19157625]

62. Knight B, Tirnitz-Parker JE, Olynyk JK. C-kit inhibition by imatinib mesylate attenuates progenitor cell expansion and inhibits liver tumor formation in mice. Gastroenterology. 2008; 135:969-979. 79, e1. [PubMed: 18602920]

63. Mejias M, Garcia-Pras E, Tiani C, Miquel R, Bosch J, Fernandez M. Beneficial effects of sorafenib on splanchnic, intrahepatic, and portocollateral circulations in portal hypertensive and cirrhotic rats. Hepatology. 2009; 49:1245-1256. [PubMed: 19137587]

64. Tanabe KK, Lemoine A, Finkelstein DM, et al. Epidermal growth factor gene functional polymorphism and the risk of hepatocellular carcinoma in patients with cirrhosis. JAMA. 2008; 299:53-60. [PubMed: 18167406]

65. Schiffer E, Housset C, Cacheux W, et al. Gefitinib, an EGFR inhibitor, prevents hepatocellular carcinoma development in the rat liver with cirrhosis. Hepatology. 2005; 41:307-314. [PubMed: 15660382]

66. Luo J, Solimini NL, Elledge SJ. Principles of cancer therapy: oncogene and non-oncogene addiction. Cell. 2009; 136:823-837. [PubMed: 19269363]

67. Weinstein IB. Cancer. Addiction to oncogenes-the Achilles heal of cancer. Science. 2002; 297:6364. [PubMed: 12098689]

68. Jain M, Arvanitis C, Chu K, et al. Sustained loss of a neoplastic phenotype by brief inactivation of MYC. Science. 2002; 297:102-104. [PubMed: 12098700]

69. Piccart-Gebhart MJ, Procter M, Leyland-Jones B, et al. Trastuzumab after adjuvant chemotherapy in HER2-positive breast cancer. N Engl J Med. 2005; 353:1659-1672. [PubMed: 16236737]

70. Bang YJ, Van Cutsem E, Feyereislova A, et al. Trastuzumab in combination with chemotherapy versus chemotherapy alone for treatment of HER2-positive advanced gastric or gastro-oesophageal junction cancer (ToGA): a phase 3, open-label, randomised controlled trial. Lancet. 2010; 376:687-697. [PubMed: 20728210]

71. Flaherty KT, Puzanov I, Kim KB, et al. Inhibition of mutated, activated BRAF in metastatic melanoma. N Engl J Med. 2010; 363:809-819. [PubMed: 20818844]

72. Solimini NL, Luo J, Elledge SJ. Non-oncogene addiction and the stress phenotype of cancer cells. Cell. 2007; 130:986-988. [PubMed: 17889643] 
73. van't Veer LJ, Bernards R. Enabling personalized cancer medicine through analysis of geneexpression patterns. Nature. 2008; 452:564-570. [PubMed: 18385730]

74. Schreiber SL, Shamji AF, Clemons PA, et al. Towards patient-based cancer therapeutics. Nat Biotechnol. 2010; 28:904-906. [PubMed: 20829823]

75. http://www.cancer.gov/.

76. Dancey J, Sausville EA. Issues and progress with protein kinase inhibitors for cancer treatment. Nat Rev Drug Discov. 2003; 2:296-313. [PubMed: 12669029]

77. Reichert JM, Rosensweig CJ, Faden LB, Dewitz MC. Monoclonal antibody successes in the clinic. Nat Biotechnol. 2005; 23:1073-1078. [PubMed: 16151394]

78. Kola I, Landis J. Can the pharmaceutical industry reduce attrition rates? Nat Rev Drug Discov. 2004; 3:711-715. [PubMed: 15286737]

79. Wilhelm SM, Adnane L, Newell P, Villanueva A, Llovet JM, Lynch M. Preclinical overview of sorafenib, a multikinase inhibitor that targets both Raf and VEGF and PDGF receptor tyrosine kinase signaling. Mol Cancer Ther. 2008; 7:3129-3140. [PubMed: 18852116]

80. Croswell JM, Kramer BS. Clinical trial design and evidence-based outcomes in the study of liver diseases. J Hepatol. 2009; 50:817-826. [PubMed: 19231015]

81. Therasse P, Arbuck SG, Eisenhauer EA, et al. New guidelines to evaluate the response to treatment in solid tumors. European Organization for Research and Treatment of Cancer, National Cancer Institute of the United States, National Cancer Institute of Canada. J Natl Cancer Inst. 2000; 92:205-216. [PubMed: 10655437]

82. Lencioni R, Llovet JM. Modified RECIST (mRECIST) assessment for hepatocellular carcinoma. Semin Liver Dis. 2010; 30:52-60. [PubMed: 20175033]

83. Cheng AL, Kang YK, Chen Z, et al. Efficacy and safety of sorafenib in patients in the Asia-Pacific region with advanced hepatocellular carcinoma: a phase III randomised, double-blind, placebocontrolled trial. Lancet Oncol. 2009; 10:25-34. [PubMed: 19095497]

84. Abou-Alfa GK, Schwartz L, Ricci S, et al. Phase II study of sorafenib in patients with advanced hepatocellular carcinoma. J Clin Oncol. 2006; 24:4293-4300. [PubMed: 16908937]

85. Muszbek N, Shah S, Carroll S, et al. Economic evaluation of sorafenib in the treatment of hepatocellular carcinoma in Canada. Curr Med Res Opin. 2008; 24:3559-3569. [PubMed: 19032137]

86. http://www.clinicaltrials.gov/.

87. Faivre S, Raymond E, Boucher E, et al. Safety and efficacy of sunitinib in patients with advanced hepatocellular carcinoma: an open-label, multicentre, phase II study. Lancet Oncol. 2009; 10:794 800. [PubMed: 19586800]

88. Zhu AX, Sahani DV, Duda DG, et al. Efficacy, safety, and potential biomarkers of sunitinib monotherapy in advanced hepatocellular carcinoma: a phase II study. J Clin Oncol. 2009; 27:3027-3035. [PubMed: 19470923]

89. Imamura H, Matsuyama Y, Tanaka E, et al. Risk factors contributing to early and late phase intrahepatic recurrence of hepatocellular carcinoma after hepatectomy. J Hepatol. 2003; 38:200 207. [PubMed: 12547409]

90. Bekaii-Saab T, Markowitz J, Prescott N, et al. A multi-institutional phase II study of the efficacy and tolerability of lapatinib in patients with advanced hepatocellular carcinomas. Clin Cancer Res. 2009; 15:5895-5901. [PubMed: 19737952]

91. Hsu CH, Shen YC, Lin ZZ, et al. Phase II study of combining sorafenib with metronomic tegafur/ uracil for advanced hepatocellular carcinoma. J Hepatol. 2010; 53:126-131. [PubMed: 20416968]

92. Kanai F, Yoshida H, Tateishi R, et al. A phase I/II trial of the oral antiangiogenic agent TSU-68 in patients with advanced hepatocellular carcinoma. Cancer Chemother Pharmacol. 2010

93. Philip PA, Mahoney MR, Allmer C, et al. Phase II study of Erlotinib (OSI-774) in patients with advanced hepatocellular cancer. J Clin Oncol. 2005; 23:6657-6663. [PubMed: 16170173]

94. Ramanathan RK, Belani CP, Singh DA, et al. A phase II study of lapatinib in patients with advanced biliary tree and hepatocellular cancer. Cancer Chemother Pharmacol. 2009; 64:777-783. [PubMed: 19169683] 
95. Thomas MB, Chadha R, Glover K, et al. Phase 2 study of erlotinib in patients with unresectable hepatocellular carcinoma. Cancer. 2007; 110:1059-1067. [PubMed: 17623837]

96. Thomas MB, Morris JS, Chadha R, et al. Phase II trial of the combination of bevacizumab and erlotinib in patients who have advanced hepatocellular carcinoma. J Clin Oncol. 2009; 27:843850. [PubMed: 19139433]

97. Yau T, Chan P, Ng KK, et al. Phase 2 open-label study of single-agent sorafenib in treating advanced hepatocellular carcinoma in a hepatitis B-endemic Asian population: presence of lung metastasis predicts poor response. Cancer. 2009; 115:428-436. [PubMed: 19107763]

98. Raoul JL, Finn R, Kang Y, et al. An open-label phase II study of first- and second-line treatment with brivanib in patients with hepatocellular carcinoma. J Clin Oncol. 2009; 27(Suppl) (abstract).

99. Siegel AB, Cohen EI, Ocean A, et al. Phase II trial evaluating the clinical and biologic effects of bevacizumab in unresectable hepatocellular carcinoma. J Clin Oncol. 2008; 26:2992-2998. [PubMed: 18565886]

100. Morelli MP, Brown AM, Pitts TM, et al. Targeting vascular endothelial growth factor receptor-1 and -3 with cediranib (AZD2171): effects on migration and invasion of gastrointestinal cancer cell lines. Mol Cancer Ther. 2009; 8:2546-2558. [PubMed: 19755510]

101. Giannelli G, Azzariti A, Sgarra C, Porcelli L, Antonaci S, Paradiso A. ZD6474 inhibits proliferation and invasion of human hepatocellular carcinoma cells. Biochem Pharmacol. 2006; 71:479-485. [PubMed: 16332356]

102. Abou-Alfa GK, Johnson P, Knox JJ, et al. Doxorubicin plus sorafenib vs doxorubicin alone in patients with advanced hepatocellular carcinoma: a randomized trial. JAMA. 2010; 304:21542160. [PubMed: 21081728]

103. Moore MJ, Goldstein D, Hamm J, et al. Erlotinib plus gemcitabine compared with gemcitabine alone in patients with advanced pancreatic cancer: a phase III trial of the National Cancer Institute of Canada Clinical Trials Group. J Clin Oncol. 2007; 25:1960-1966. [PubMed: 17452677]

104. Cascinu S, Jelic S. Pancreatic cancer: ESMO clinical recommendations for diagnosis, treatment and follow-up. Ann Oncol. 2009; 20(Suppl 4):37-40. [PubMed: 19454458]

105. Neumann PJ, Rosen AB, Weinstein MC. Medicare and cost-effectiveness analysis. N Engl J Med. 2005; 353:1516-1522. [PubMed: 16207857]

106. Shih YC, Halpern MT. Economic evaluations of medical care interventions for cancer patients: how, why, and what does it mean? CA Cancer J Clin. 2008; 58:231-244. [PubMed: 18596196]

107. Earle CC, Chapman RH, Baker CS, et al. Systematic overview of cost-utility assessments in oncology. J Clin Oncol. 2000; 18:3302-3317. [PubMed: 10986064]

108. Nadler E, Eckert B, Neumann PJ. Do oncologists believe new cancer drugs offer good value? Oncologist. 2006; 11:90-95. [PubMed: 16476830]

109. Ubel PA, Hirth RA, Chernew ME, Fendrick AM. What is the price of life and why doesn't it increase at the rate of inflation? Arch Intern Med. 2003; 163:1637-1641. [PubMed: 12885677]

110. Mittmann N, Au HJ, Tu D, et al. Prospective cost-effectiveness analysis of cetuximab in metastatic colorectal cancer: evaluation of National Cancer Institute of Canada Clinical Trials Group CO.17 trial. J Natl Cancer Inst. 2009; 101:1182-1192. [PubMed: 19666851]

111. Mandal S, Moudgil M, Mandal SK. Rational drug design. Eur J Pharmacol. 2009; 625:90-100. [PubMed: 19835861]

112. http://www.fda.gov/.

113. Cohen MH, Williams GA, Sridhara R, Chen G, Pazdur R. FDA drug approval summary: gefitinib (ZD1839) (Iressa) tablets. Oncologist. 2003; 8:303-306. [PubMed: 12897327]

114. Thatcher N, Chang A, Parikh P, et al. Gefitinib plus best supportive care in previously treated patients with refractory advanced non-small-cell lung cancer: results from a randomised, placebo-controlled, multicentre study (Iressa Survival Evaluation in Lung Cancer). Lancet. 2005; 366:1527-1537. [PubMed: 16257339]

115. Kobayashi S, Boggon TJ, Dayaram T, et al. EGFR mutation and resistance of non-small-cell lung cancer to gefitinib. N Engl J Med. 2005; 352:786-792. [PubMed: 15728811]

116. Tsao MS, Sakurada A, Cutz JC, et al. Erlotinib in lung cancer - molecular and clinical predictors of outcome. N Engl J Med. 2005; 353:133-144. [PubMed: 16014883] 
117. Maemondo M, Inoue A, Kobayashi K, et al. Gefitinib or chemotherapy for non-small-cell lung cancer with mutated EGFR. N Engl J Med. 2010; 362:2380-2388. [PubMed: 20573926]

118. Jonker DJ, O'Callaghan CJ, Karapetis CS, et al. Cetuximab for the treatment of colorectal cancer. N Engl J Med. 2007; 357:2040-2048. [PubMed: 18003960]

119. Karapetis CS, Khambata-Ford S, Jonker DJ, et al. K-ras mutations and benefit from cetuximab in advanced colorectal cancer. N Engl J Med. 2008; 359:1757-1765. [PubMed: 18946061]

120. Allegra CJ, Jessup JM, Somerfield MR, et al. American Society of Clinical Oncology provisional clinical opinion: testing for KRAS gene mutations in patients with metastatic colorectal carcinoma to predict response to anti-epidermal growth factor receptor monoclonal antibody therapy. J Clin Oncol. 2009; 27:2091-2096. [PubMed: 19188670]

121. Llovet JM, Bruix J. Molecular targeted therapies in hepatocellular carcinoma. Hepatology. 2008; 48:1312-1327. [PubMed: 18821591] 
Efficacy of tailored molecular therapy in colorectal cancer (EGFR inhibition and KRAS mutation status)

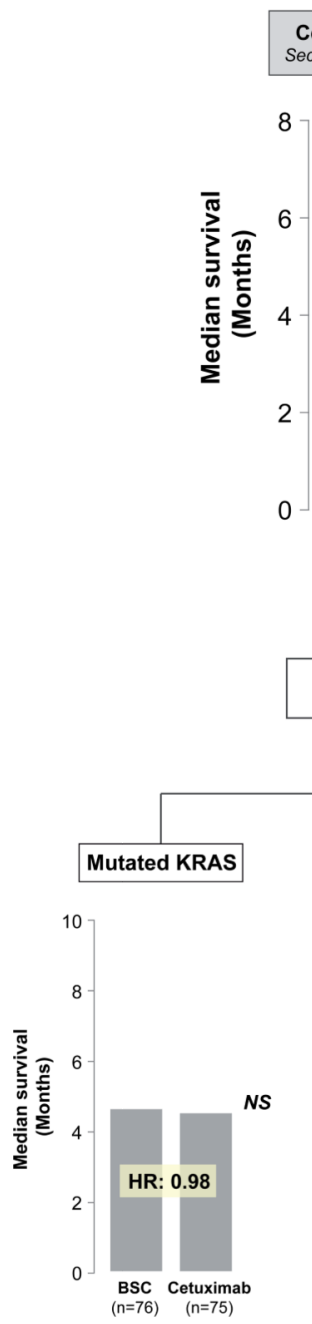

Cetuximab (EGFR inhibitor)

cond-line, advanced CCR ( $n=57$
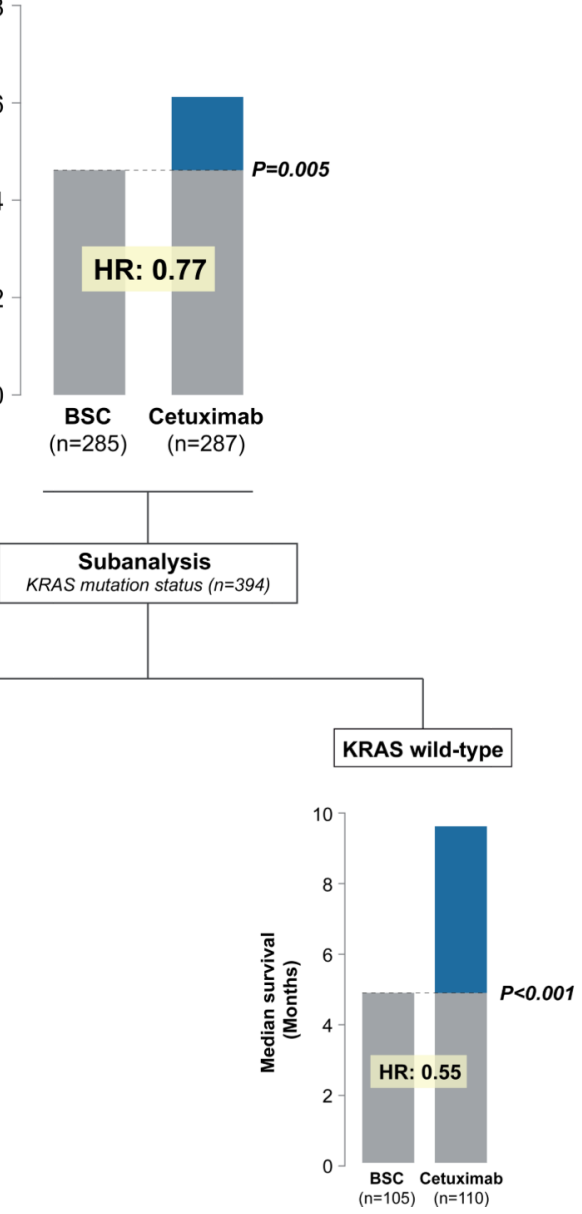

Systemic therapy in advanced colorectal cancer (Survival trends in 1990-2005)

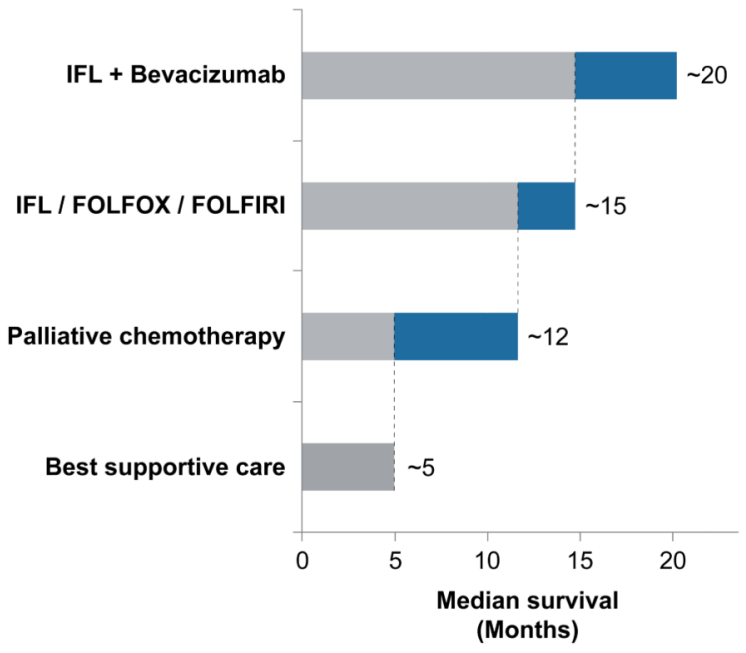

(Months)

Figure 1. Targeted and Systemic Therapies for CRC

In a trial of cetuximab as a second-line therapy for patients with CRC, those with tumors that expressed wild-type KRAS mutation had longer survival times than patients whose tumor cells had KRAS mutations (right panel). Data were obtained from 2 studies analyzing a total of 572 CRC patients ${ }^{118,119}$. Survival trends for patients with advanced CRC from 1990 to 2005 , based on treatment. Those that received a combination of chemotherapy and targeted therapy (an anti-angiogenic agent), and the longest survival times.

IFL, irinotecan, bolus of 5-fluoruoracil, and leucovorin; FOLFOX, 5-fluoruracil, leucovorin, and oxaliplatin; FOLFIRI, irinotecan, infusion of 5-fluoruoracil, and leucovorin. 

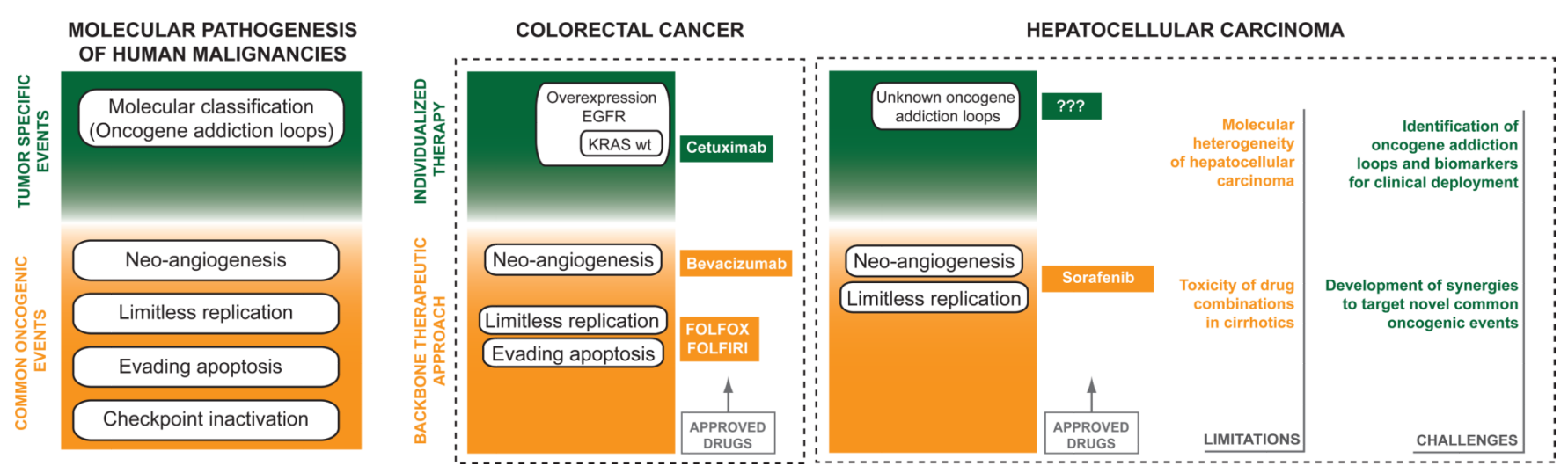

Figure 2.

Individualizing therapy for patients with HCC. Therapeutics might be developed to target factors that contribute to progression of most tumor types (therapeutic approach) and factors required for progression of HCC, specifically (oncogene addiction). This approach is used to treat patients with CRC and other types of cancer. 
Table 1

Molecular therapies (including tyrosine kinase inhibitors, monoclonal antibodies and oligonucleotide antisense) currently under evaluation in HCC. Data accessed on February 2011.

\begin{tabular}{|c|c|c|c|c|}
\hline & Drugs & Phases & Trials (n) & Targets \\
\hline 1 & Sorafenib & $1,1-2,2,3,4$ & 65 & BRAF, VEGFR, PDGFR \\
\hline 2 & Erlotinib & $1,1-2,2,3$ & 13 & EGFR \\
\hline 3 & Everolimus & $1,1-2,2,3$ & 7 & MTORC1 \\
\hline 4 & Brivanib & $1,2,3$ & 6 & FGFR, VEGFR, PDGFR \\
\hline 5 & Sunitinib & 2,3 & 6 & VEGFR, PDGFR, CKIT \\
\hline 6 & Rapamycin & $1,2-3,3$ & 5 & MTORC1 \\
\hline 7 & Linifanib & 2,3 & 2 & VEGF, PDGFR \\
\hline 8 & PI-88 & 2,3 & 2 & Endo-beta-D-glucuronidase heparanase \\
\hline 9 & Ramucirumab & 3 & 1 & VEGFR2 \\
\hline 10 & Bevacizumab & $1,1-2,2$ & 20 & VEGF \\
\hline 11 & AZD6244 & $1-2,2$ & 4 & MEK \\
\hline 12 & Bortezomib & 1,2 & 4 & Proteasome \\
\hline 13 & TAC-101 & $1-2,2$ & 4 & RAR-a \\
\hline 14 & Cediranib & 1,2 & 3 & VEGFR \\
\hline 15 & Cetuximab & 1,2 & 3 & EGFR \\
\hline 16 & Cixutumumab & 1,2 & 3 & IGF-1R \\
\hline 17 & Temsirolimus & 1,2 & 3 & MTORC1 \\
\hline 18 & ARQ197 & 1,2 & 2 & MET \\
\hline 19 & BIBF1120 & 2 & 2 & VEGFR, PDGFR, FGFR \\
\hline 20 & Dasatinib & 2 & 2 & BCR-ABL \\
\hline 21 & GC33 & 1 & 2 & GPC3 \\
\hline 22 & Gefitinib & 2 & 2 & EGFR \\
\hline 23 & Lapatinib & 2 & 2 & EGFR, HER2/neu \\
\hline 24 & Licartin & 2,4 & 2 & HAb18G/CD147 \\
\hline 25 & Pazopanib & 2 & 2 & VEGFR, PDGFR, CKIT \\
\hline 26 & Alvocidib & 1,2 & 2 & Cyclin-dependent kinase \\
\hline 27 & AEG35156 & $1-2$ & 1 & XIAP \\
\hline 28 & AMG386 & 2 & 1 & Angiopoietin \\
\hline 29 & AVE1642 & 1,2 & 1 & IGF-1R \\
\hline 30 & AZD8055 & $1-2$ & 1 & MTORC1, MTORC2 \\
\hline 31 & Regorafenib & 2 & 1 & VEGFR, TIE-2 \\
\hline 32 & BIIB022 & $1-2$ & 1 & IGF-1R \\
\hline 33 & Belinostat & $1-2$ & 1 & Histone deacetylase \\
\hline 34 & CS-1008 & 2 & 1 & TRAIL \\
\hline 35 & CT-011 & $1-2$ & 1 & PD1 \\
\hline 36 & E7080 & $1-2$ & 1 & VEGFR, FGFR, SCFR \\
\hline
\end{tabular}




\begin{tabular}{|c|l|c|c|l|}
\hline & Drugs & Phases & Trials (n) & Targets \\
\hline 37 & Foretinib & 1 & 1 & MET \\
\hline 38 & IDN-6556 & 2 & 1 & Caspase \\
\hline 39 & IMC-1121B & 2 & 1 & VEGFR2 \\
\hline 40 & IMC-A12 & 2 & 1 & IGF-1R \\
\hline 41 & Ispinesib & 2 & 1 & Kinesin spindel protein \\
\hline 42 & LBH589 & 1 & 1 & Histone deacetylase \\
\hline 43 & LY2181308 & $1-2$ & 1 & Survivin \\
\hline 44 & Lonafarnib & 2 & 1 & Farnesyl-OH-transferase \\
\hline 45 & MLN8237 & 2 & 1 & Aurora kinase \\
\hline 46 & Mapatumumab & $1-2$ & 1 & TRAIL \\
\hline 47 & OSI-906 & 2 & 1 & IGF-1R, IR \\
\hline 48 & Oblimersen & 2 & 1 & BCL2 \\
\hline 49 & Panobinostat & 1 & 1 & Histone deacetylase \\
\hline 50 & Resminostat & 2 & 1 & Histone deacetylase \\
\hline 51 & TSU-68 & $1-2$ & 1 & VEGFR, FGFR, PDGFR \\
\hline 52 & Talabostat & 1 & 1 & Dipeptidyl peptidases \\
\hline 53 & Tremelimumab & 2 & 1 & B7-CD28 \\
\hline 54 & Vandetanib & 2 & 1 & EGFR, VEGFR, RET \\
\hline 55 & Vorinostat & 1 & 1 & Histone deacetylase \\
\hline 56 & Z-208 & $1-2$ & 1 & RAR \\
\hline & & & & \\
\hline 50 & 1 & 1 & 1 & 1 \\
\hline
\end{tabular}




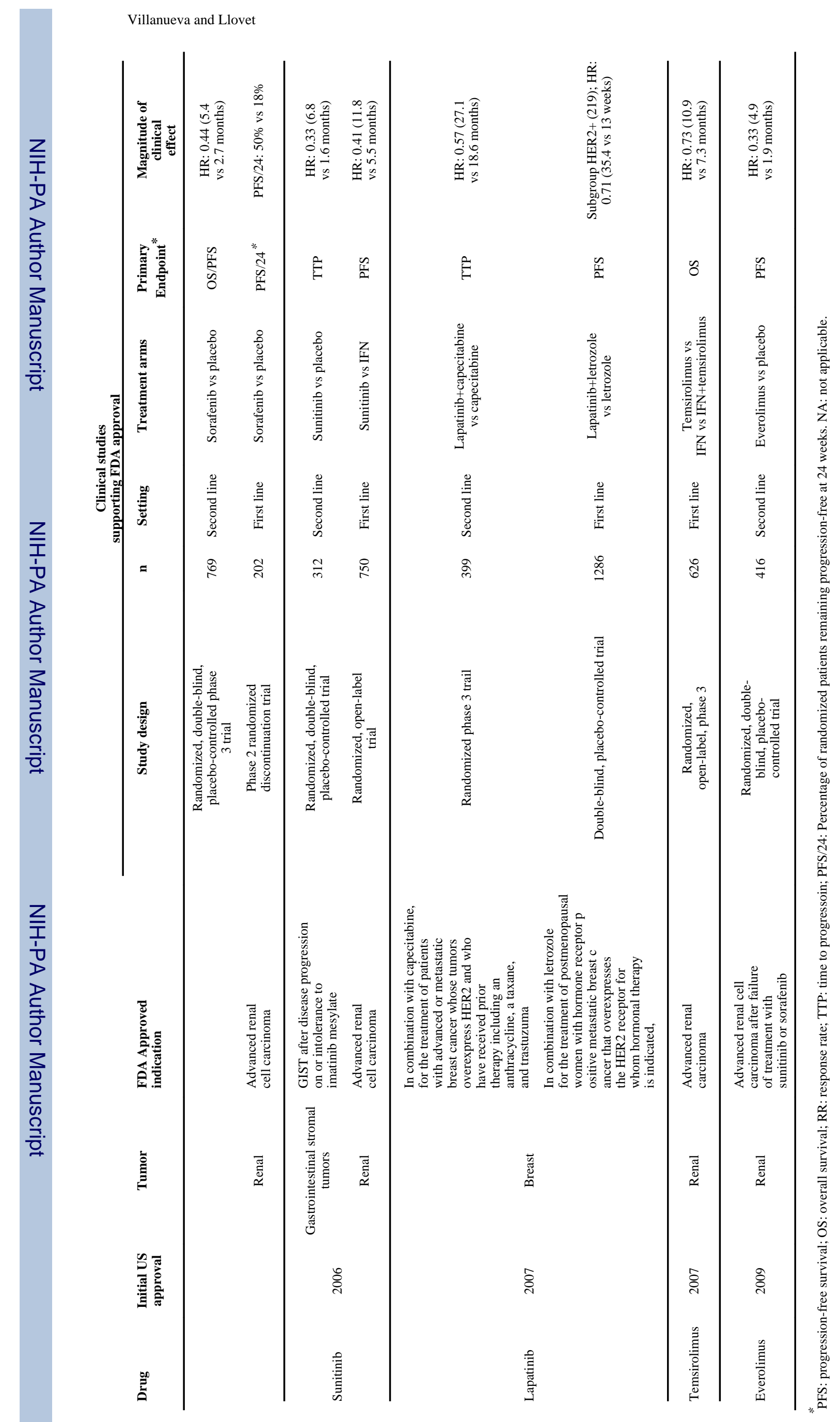




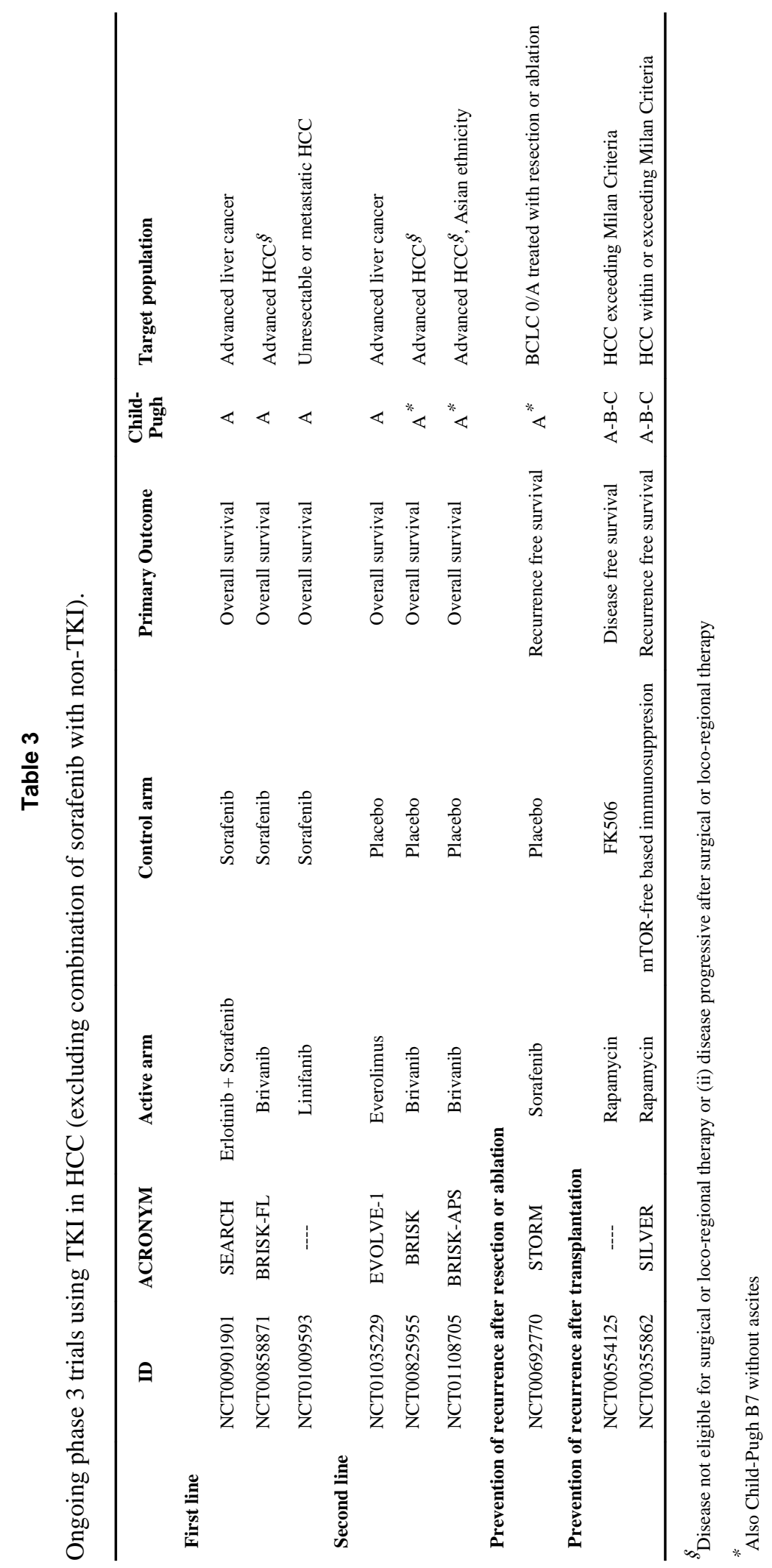

Gastroenterology. Author manuscript; available in PMC 2013 June 14. 


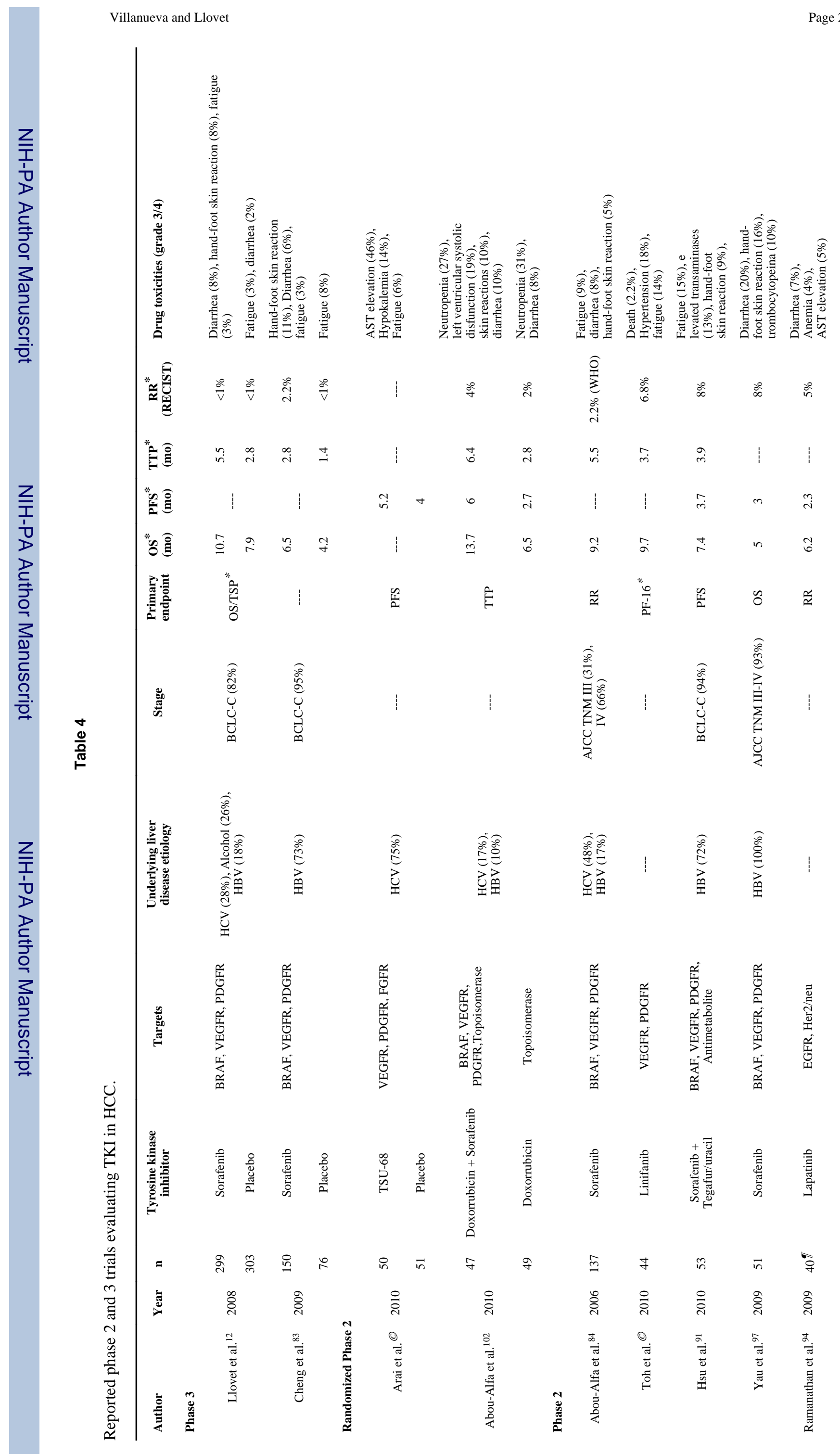




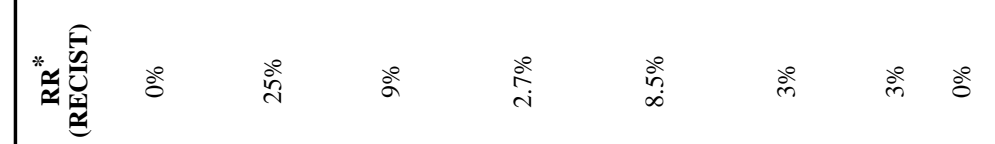

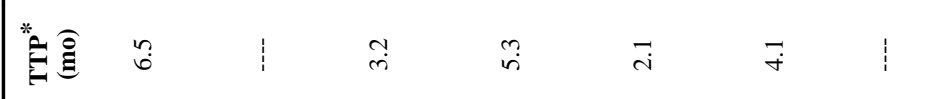

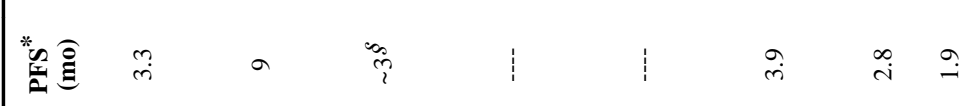

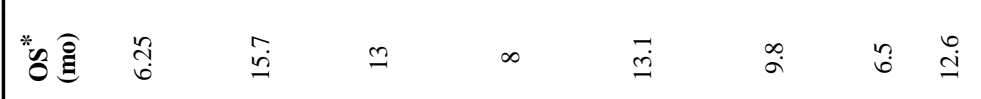

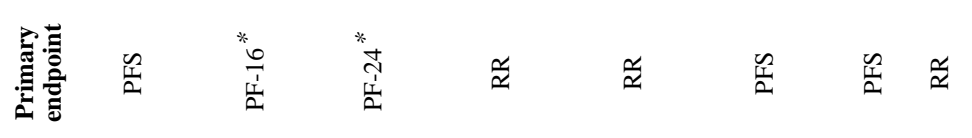

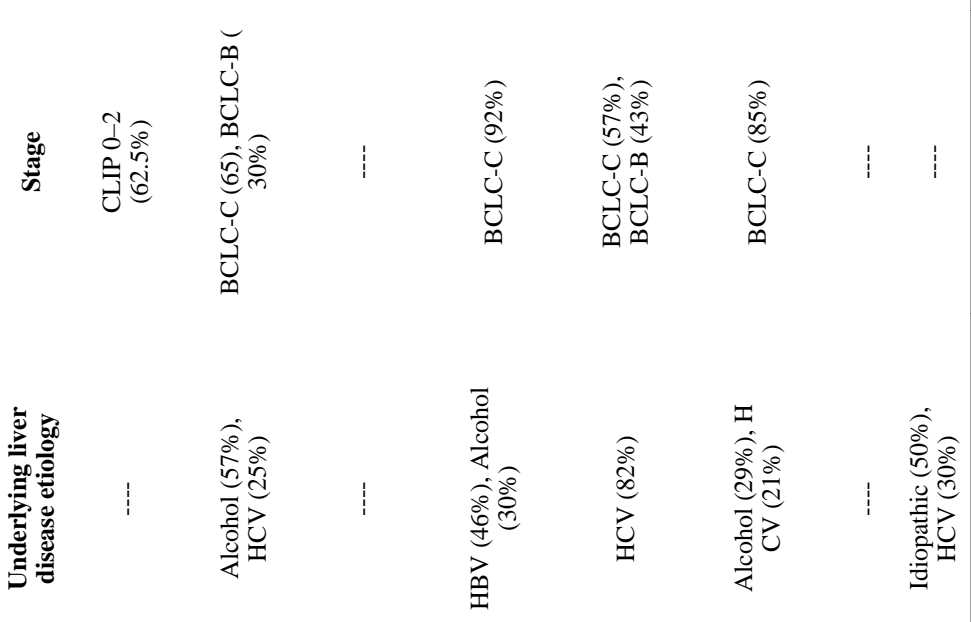
$=q$ क $\infty$ क

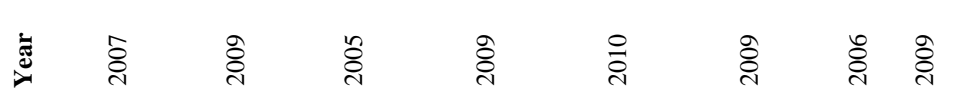

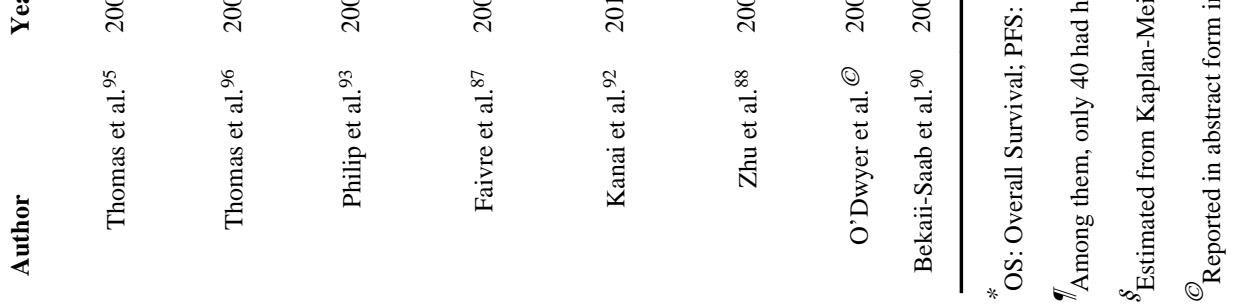

